\title{
In vivo TSPO imaging in patients with multiple sclerosis: a brain PET study with $\left[{ }^{18}\right.$ F]FEDAA1106
}

\author{
Akihiro Takano ${ }^{1 *}$, Fredrik Piehl ${ }^{2}$, Jan Hillert ${ }^{2}$, Andrea Varrone ${ }^{1}$, Sangram Nag ${ }^{1}$, Balázs Gulyás ${ }^{1}$, Per Stenkrona ${ }^{1}$, \\ Victor L Villemagne ${ }^{3}$, Christopher C Rowe ${ }^{3}$, Richard Macdonell ${ }^{4}$, Nabil Al Tawil ${ }^{5}$, Thomas Kucinski², \\ Torsten Zimmermann ${ }^{6}$, Marcus Schultze-Mosgau ${ }^{6}$, Andrea Thiele $^{6}$, Anja Hoffmann ${ }^{6+}$ and Christer Halldin ${ }^{1 \dagger}$
}

\begin{abstract}
Background: The activation of microglia, in general, and the upregulation of the translocator protein (18 $\mathrm{kDa})$ (TSPO) system, in particular, are key features of neuroinflammation, of which the in vivo visualization and quantitative assessment are still challenging due to the lack of appropriate molecular imaging biomarkers. Recent positron emission tomography (PET) studies using TSPO radioligands such as $\left[{ }^{11} \mathrm{C}\right]$ PK11195 and $\left[{ }^{11} \mathrm{C}\right]$ PBR28 have indicated the usefulness of these PET biomarkers in patients with neuroinflammatory diseases, including multiple sclerosis (MS). [ ${ }^{18}$ F]FEDAA1106 is a recently developed PET radioligand for the in vivo quantification of TSPO. In the present study, we aimed at investigating the diagnostic usefulness of $\left[{ }^{18} \mathrm{~F}\right] \mathrm{FEDAA} 1106$ in patients with MS.

Methods: Nine patients (three on the interferon beta therapy and six without immunomodulatory therapy; seven females/two males; age $34.2 \pm 9.1$ years old) with relapsing-remitting MS in acute relapse and with gadolinium (Gd)-enhancing lesion(s) in the magnetic resonance imaging (MRI) scans and five healthy controls (four females/one male, age $38.0 \pm 9.7$ years old) were investigated in this study. Genetic information about the TSPO binding could not be obtained because knowledge about the importance of genetic background for TSPO binding was not available at the time the study was performed. Dynamic PET measurements were performed using an ECAT EXACT HR system (CTI/Siemens, Knoxville, TN, USA) for a total of $150 \mathrm{~min}$, with a 30-min break after the injection of 153.4 $\pm 10.2 \mathrm{MBq}$ of $\left[{ }^{18} \mathrm{~F}\right] \mathrm{FEDAA} 1106$. Metabolite-corrected arterial plasma samples were used to calculate the input function. PET data were analyzed in the following ways: (1) region-of-interest analysis for cortical and subcortical regions was performed using a two-tissue compartment kinetic model in order to estimate binding potentials $\left(\mathrm{BP}_{\mathrm{ND}}\right)$ and distribution volume $(\mathrm{VT}),(2)$ the feasibility of the estimation of $\mathrm{BP}_{\mathrm{ND}}$ and $\mathrm{VT}$ was investigated for MS lesions, and (3) VT parametric images by a Logan plot and standard uptake value (SUV) images were visually compared with the corresponding MRI, focusing on MRI-identified MS lesions.

Results: There were no significant differences in the $\mathrm{BP}_{\mathrm{ND}}$ or $\mathrm{VT}$ values between patients with MS and healthy controls. Robust $\mathrm{BP}_{\mathrm{ND}}$ and $\mathrm{VT}$ values could not be obtained for most MS lesions due to noisy time-activity curves. Visual inspection of VT and SUV images in all nine patients did not reveal high uptake of the radioligand inside and beyond MRI-identified active MS lesions with the exception of one Gd-enhanced MS lesion in the whole patient population.
\end{abstract}

Conclusions: In our study, $\left[{ }^{18} \mathrm{~F}\right]$ FEDAA1106 as a PET radioligand could neither differentiate patients with MS from healthy controls nor detect active plaques in the brain of MS patients. Stratification with respect to genetics and binder status might help to uncover the differences between the groups, which could not be detected here. (Continued on next page)

\footnotetext{
* Correspondence: akihiro.takano@ki.se

†Equal contributors

${ }^{1}$ Center for Psychiatric Research, Department of Clinical Neuroscience,

Karolinska Institutet, Stockholm SE-171 77, Sweden

Full list of author information is available at the end of the article
}

\section{实 Springer}

(c) 2013 Takano et al.; licensee Springer. This is an Open Access article distributed under the terms of the Creative Commons Attribution License (http://creativecommons.org/licenses/by/2.0), which permits unrestricted use, distribution, and reproduction in any medium, provided the original work is properly cited. 


\section{Background}

Multiple sclerosis (MS) is characterized by neuroinflammation, demyelination, and axonal loss in the brain. The activation of microglia cells is one of the main components of neuroinflammation. The expression of the translocator protein (TSPO) is reported to increase in activated microglia as well as infiltrating macrophages and reactive astrocytes in MS [1]. The evaluation of the TSPO system may provide us with information about the activity of the disease and its progression. Recently, TSPO has been visualized and quantified in vivo by positron emission tomography (PET) with various radioligands. PET studies, using $\left[{ }^{11} \mathrm{C}\right] \mathrm{PK} 11195$, have reported increased binding in areas of focal MS lesions defined by MRI scans, especially Gd-enhanced lesions [2]. $\left[{ }^{11} \mathrm{C}\right]$ PBR28 displayed significantly higher white matter-gray matter ratios in MS patients than in healthy controls as well as increased radioligand binding in areas beyond focal MRI-defined MS lesions [3]. $\left[{ }^{11} \mathrm{C}\right]$ vinpocetine exhibited local radioligand uptakes in the vicinity of the MRI-identified MS lesions [4].

$\left[{ }^{18} \mathrm{~F}\right]$ FEDAA1106 is a recently developed PET radioligand for the quantification of TSPO in vivo. Compared with PBR28 and PK11195, FEDAA1106 has higher affinity to TSPO $(\mathrm{Ki}=0.078 \mathrm{nM})[5] .{ }^{18} \mathrm{~F}$ radioligands have an advantage over ${ }^{11} \mathrm{C}$ radioligands with respect to the longer half-life (109 vs $20 \mathrm{~min})$, which makes transportation of the ligands to PET centers, without cyclotrons, possible. In the present study, we have investigated the diagnostic potential of $\left[{ }^{18} \mathrm{~F}\right]$ FEDAA1106 to detect MS lesions and to differentiate between patients with MS and healthy volunteers.

\section{Methods}

\section{Radiochemistry}

$\left[{ }^{18} \mathrm{~F}\right]$ FEDAA1106 was synthesized, as described previously [6]. The mean injected radioactivity was $153.4 \pm 10.2$ MBq. The mass injected was less than $2.7 \mu \mathrm{g}$.

The injection of the radioligand was performed as a bolus over $30 \mathrm{~s}$ via an inserted intravenous line, and the cannula was flushed with $10 \mathrm{~mL}$ of saline.

\section{Subjects}

The study was conducted in line with the Helsinki Declaration and approved by the Independent Ethics Committee and the Radiation Safety Committee of the Karolinska University Hospital as well as the Swedish Medical Products Agency. The study was registered at
www.ClinicalTrials.gov. Nine patients (seven females/two males; age $34.2 \pm 9.1$ years old) with relapsing-remitting MS in acute relapse were included in this study; six of them were drug-naive, and three patients were on betainterferon treatment at the time of the PET measurements. All the patients fulfilled the following criteria: clinical signs of a relapse within a maximum of 21 days before screening, at least two T2 lesions at different locations and at least one Gd-enhanced lesion in the MRI screening and a score between 0 and 5 points on the Kurtzke expanded disability status scale. Five healthy volunteers (four females/one male, age $38.0 \pm 9.7$ years old) were included in this study. Subjects who had other chronic diseases or conditions or who used concomitant medication that could interfere with measurements, such as treatment with benzodiazepines, were excluded. Likewise, any unstable medical conditions as well as patients with either evidence or history of a severe psychiatric disorder were judged ineligible for this study. Healthy volunteers with abnormal MRI findings for their ages were also excluded. Informed written consent was obtained from all the subjects. The time span between the MRI screening and the PET scan was $3.6 \pm 1.4$ days ( 1 to 6 days) for MS patients and $9.8 \pm 3.9$ days (5 to 15 days) for healthy volunteers.

\section{MRI measurements}

MRI T1-weighted images were acquired using the $1.5 \mathrm{~T}$ GE Signa system (GE Medical Systems, Milwaukee, WI, USA). T1-weighted, T2-weighted, and fluid-attenuated inversion recovery (FLAIR) images were acquired for both MS patients and healthy controls. Gd-enhanced T1 images were also acquired for MS patients.

\section{PET measurements with arterial blood sampling}

PET measurements were performed on an ECAT Exact HR 47 PET system (CTI/Siemens, Knoxville, TN, USA) operated in $3 \mathrm{D}$ mode. The scanner's three-ring detector block architecture provides a $15-\mathrm{cm}$-wide field of view. The transversal resolution in the reconstructed image is about $3.8 \mathrm{~mm}$ full width at half maximum (FWHM), and the axial resolution is $3.125 \mathrm{~mm}$ [7]. Attenuation correction was obtained with three rotating ${ }^{68} \mathrm{Ge}$ line sources. Emission data of $\left[{ }^{18} \mathrm{~F}\right]$ FEDAA1106 were acquired over 150 min with a 30-min break between 60 and 90 min after the radioligand injection. The frame times were $20 \mathrm{~s} \times 6$ frames, $1 \mathrm{~min} \times 4$ frames, $3 \mathrm{~min} \times 6$ frames, $6 \mathrm{~min} \times 6$ frames in the first part, and $6 \mathrm{~min} \times 10$ frames in the 
second part. Images were reconstructed using the standard filtered back projection with a 2-mm Hanning filter.

A catheter was inserted in the radial artery, and arterial blood was collected continuously for 5 min using an automated blood-sampling system at a speed of $5 \mathrm{~mL} / \mathrm{min}$ (ABSS; Allog AB, Mariefred, Sweden). Blood samples (4 mL) were drawn at 2.5, 9, 20, 30, 40, 60, 90, 120, and $150 \mathrm{~min}$ for blood and plasma radioactivity and metabolite correction.

\section{Metabolite analysis}

A reversed-phase high-performance liquid chromatography (HPLC) method was used to determine the percentages of radioactivity in plasma that corresponded to both unchanged $\left[{ }^{18} \mathrm{~F}\right]$ FEDAA1106 and its radioactive metabolites during the course of the PET measurement. Plasma $(0.5 \mathrm{~mL})$, obtained after centrifugation of blood at $2,000 \times g$ for $2 \mathrm{~min}$, was mixed with acetonitrile $(0.7 \mathrm{~mL})$. After additional centrifugation of the acetonitrile-plasma mixture $(1.1 \mathrm{~mL})$ at $2,000 \times g$ for 2 more min, the supernatant was measured in a $\mathrm{NaI}$ well counter and then analyzed by radio-HPLC.

The radio-HPLC system consisted of an interface module (D-7000; Hitachi, Chiyoda-ku, Japan), an L-7100 pump (Hitachi), an injector (Rheodyne model 7125 with a 1.0-mL loop; IDEX Corporation, Oak Harbor, WA, USA), and an absorbance detector (L-7400; $254 \mathrm{~nm}$; Hitachi) in series with a radiation detector (Radiomatic 150TR; Packard, Meriden, CT, USA) equipped with a PET flow cell $(600 \mu \mathrm{L}$ cell). A $\mu$-Bondapak-C18 column (300 mm $\times 7.8 \mathrm{~mm}, 10 \mu \mathrm{m}$; Waters, Milford, MA, USA) was used for metabolite analysis. The following gradient settings were used with a flow rate of $6.0 \mathrm{~mL} / \mathrm{min}$ : solvents - acetonitrile (A) and phosphoric acid (10 mM) (B); time $0 \min 25(\mathrm{~A})$ and $75(\mathrm{~B})$; time $4.5 \mathrm{~min} 80(\mathrm{~A})$ and $20(\mathrm{~B})$; time $8.0 \mathrm{~min} 30(\mathrm{~A})$ and $70(\mathrm{~B})$; and time $10.0 \mathrm{~min} 25(\mathrm{~A})$ and $75(\mathrm{~B})$.

\section{Image data analysis}

Data analyses were performed focusing on the following three main points: kinetic compartment model analysis for brain anatomical regions, feasibility of estimation of outcome measures for MS lesions, and visual inspection of PET images. Group differences between patients with MS and control subjects were intended to be investigated by the evaluation of brain anatomical regions. As Gd (+) and/or T2/FLAIR high-intensity lesions were considered to reflect on inflammatory demyelization, and the increase of TSPO binding was reported in such areas in previous PET studies [2,8], the feasibility of a quantitative evaluation of MRI-defined MS lesions was explored. In one of the previous PET studies [3], high TSPO binding was reported in the areas beyond the MRI-defined MS lesions. Additionally, visual inspection of the PET images was performed in order to detect such changes.

\section{Kinetic analysis for brain anatomical regions}

PET images of the first and second parts were coregistered to the T1-weighted MRI using an SPM5 software (Wellcome Department of Imaging Neuroscience, London, UK). Regions of interest were manually delineated on the individual T1-weighted MRIs. The following regions were defined: frontal cortex, orbitofrontal cortex, lateral temporal cortex, insular cortex, parietal cortex, occipital cortex, anterior cingulate cortex, posterior cingulate cortex, caudate, putamen, thalamus, hippocampus, cerebellum, midbrain, and pons. A VOI for the whole grey matter was obtained from the segmented MRI. Time-activity curves for regions of interest (ROIs) were generated by applying the ROIs to the corresponding dynamic PET data.

In this study, binding potential $\left(\mathrm{BP}_{\mathrm{ND}}\right)$ and total distribution volume (VT), as outcome measures for $\left[{ }^{18} \mathrm{~F}\right]$ FEDAA1106 binding and brain distribution, were calculated using a two-tissue compartment (2TC) model [9]. Comparisons between patients with MS and control subjects were made for $\mathrm{BP}_{\mathrm{ND}}$ and $\mathrm{VT}$ values, respectively. In addition, a medication-dependent stratification of the MS group was made.

\section{Feasibility of estimation of $\mathrm{BP}_{\mathrm{ND}}$ and VT for MS lesions} In the MRI brain images of MS patients, ROIs were delineated on MRI-defined MS lesions revealed by FLAIR and T2 and T1 Gd-enhanced scans. We focused on the MRI-defined MS lesions of the following two groups: Gd-enhanced MS lesions (total 49 lesions) and non-Gd-enhanced-but-T2/FLAIR-high-intensity MS lesions (total 159 lesions).

Time-activity curves for each MS lesion as well as for summed subgroups were generated by applying the ROIs to the dynamic PET data. $\mathrm{BP}_{\mathrm{ND}}$ and VT were calculated by $2 \mathrm{TC}$.

\section{Visual inspection of PET images}

For visual inspection of PET images, VT and standard uptake value (SUV) images were generated. VT parametric images were generated using the Logan plot $\left(\mathrm{T}^{*}=48 \mathrm{~min}\right)$ [10]. SUV images were generated from the 90-to-150-min PET images.

The parametric images were visually compared with MRI images, focusing on MRI-defined MS lesions.

Kinetic analysis and generation of parametric images were performed using the software package PMOD (PMOD 3.0, PMOD Group, Zurich, Switzerland). 


\section{Results and discussion Results}

\section{Kinetic analysis for brain regions}

When all MS patients were compared with control subjects, there was no significant difference of $\mathrm{BP}_{\mathrm{ND}}$ or $\mathrm{VT}$ in any of the evaluated regions. Furthermore, when the MS patients were divided based on the drug treatment, there was no significant difference of $\mathrm{BP}_{\mathrm{ND}}$ or $\mathrm{VT}$ among the three groups: MS without treatment, MS with treatment, and normal control (Figure 1; Tables 1 and 2).

\section{Feasibility of estimation of $B P_{N D}$ and $V T$ for MS lesions}

The number of MS lesions detected by MRI for each subject is shown in Table 3. The size of the largest five MS lesions in each subject is shown in Table 3. The size of most MS lesions determined by MRI was below $1 \mathrm{~cm}^{3}$. $\mathrm{BP}_{\mathrm{ND}}$ and VT values estimated by the $2 \mathrm{TC}$ model were obtained for the five largest MS lesions of each case (Table 4), but these values were not robust for a single MS lesion on its own. However, even after combining all the MS lesions of a given characteristic (Gd-enhancing or high signal intensity in T2 and/or FLAIR) in each subject to cover a larger area of interest, the calculated $\mathrm{VT}$ and $\mathrm{BP}_{\mathrm{ND}}$ of the combined regions were unrealistically high in some MS lesions and were not robustly obtained (Table 5).

\section{Visual inspection of PET images}

Only one of the Gd-enhanced MS lesions was visually recognized as having higher accumulation when compared to other brain regions in SUV and VT images (Figure 2).

Although some other MRI-defined MS lesions with or without Gd-uptake may also have moderate uptake, this uptake was not clearly higher compared to the surrounding cortical regions. In areas beyond MRI-defined
MS lesions, no obvious higher uptake of the radioligand was detected.

\section{Discussion}

\section{Kinetic analysis for brain regions}

In the present study, we have not detected significant differences in $\mathrm{BP}_{\mathrm{ND}}$ and $\mathrm{VT}$ as outcome measures of $\left[{ }^{18}\right.$ F]FEDAA1106 binding and brain distribution between MS patients and healthy controls in either the whole gray matter or in different brain regions.

There are only limited data available for the imaging of neuroinflammation with TSPO ligands in MS patients, and the patient populations in these studies differ significantly, which makes interpretation and comparison between the studies difficult. Moreover, most of the previous studies did not focus on one clinical subtype of MS but included different forms (e.g., relapsingremitting as well as secondary progressive diseases), which might confound the results as well.

Initial data obtained with $\left[{ }^{11} \mathrm{C}\right] \mathrm{PK} 11195$ on postmortem brain tissue and in a pilot imaging study in two patients showed radioligand binding/uptake and suggested that ligand uptake correlates with the activity of a lesion [11]. An early study with 12 patients using $\left[{ }^{11} \mathrm{C}\right]$ PK11195 showed some increases in focal binding in brains of MS patients and described a certain overlap to signal changes in the MR in single patients [1]; however, the regional analysis in this study was limited as only the brainstem and thalamus have been evaluated. Another PET study with $\left[{ }^{11} \mathrm{C}\right]$ PK11195 in 22 MS patients suggested that ligand uptake was increased in Gdenhancing lesions compared to normal white matter [2]. However, this study was lacking a more detailed comparison of different brain regions. A more recent PET study using $\left[{ }^{11} \mathrm{C}\right]$ PBR28 as TSPO ligand could not show significant differences with respect to the brain
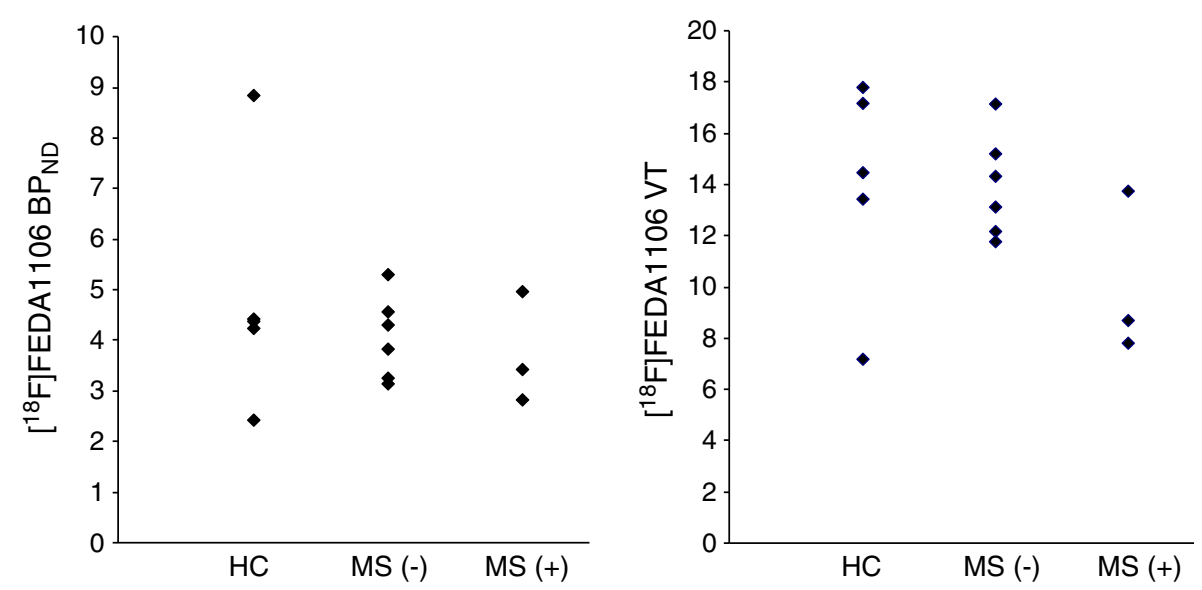

Figure 1 Comparison of $\mathrm{BP}_{\mathrm{ND}}$ (left) and VT (right) of $\left[{ }^{18} \mathrm{~F}\right] \mathrm{FEDAA} 1106$ in whole gray matter among MS patients. Six without treatment $(\mathrm{MS}(-))$, three with treatment $(\mathrm{MS}(+))$, and five healthy controls $(\mathrm{HC})$. There were no significant differences of $\mathrm{BP}_{\mathrm{ND}}$ or VT. 
Table 1 Regional $\mathrm{BP}_{\mathrm{ND}}$ values among MS patients and healthy controls

\begin{tabular}{|c|c|c|c|c|c|c|c|c|c|}
\hline \multirow[t]{2}{*}{ Region } & \multicolumn{3}{|c|}{ Six MS naive } & \multicolumn{3}{|c|}{ Three MS treatment $(+)$} & \multicolumn{3}{|c|}{ Five $\mathrm{HC}$} \\
\hline & Mean & Min & Max & Mean & Min & Max & Mean & Min & Max \\
\hline Whole gray matter & 4.1 & 3.2 & 5.3 & 3.7 & 2.8 & 5.0 & 4.9 & 2.4 & 8.9 \\
\hline ACC & 4.5 & 2.7 & 7.1 & 3.4 & 2.1 & 5.5 & 5.8 & 2.5 & 13.5 \\
\hline Caudate & 3.7 & 2.1 & 4.7 & 3.5 & 2.7 & 4.8 & 5.1 & 2.1 & 9.5 \\
\hline Putamen & 4.1 & 3.2 & 5.2 & 3.6 & 2.2 & 4.9 & 4.3 & 2.1 & 8.2 \\
\hline Thalamus & 4.5 & 3.4 & 5.9 & 5.2 & 2.8 & 8.8 & 6.1 & 2.4 & 13.9 \\
\hline Cerebellum & 4.2 & 3.2 & 5.1 & 3.7 & 2.9 & 4.9 & 4.9 & 2.4 & 9.1 \\
\hline Frontal cortex & 4.2 & 3.3 & 5.6 & 4.0 & 2.9 & 5.4 & 5.1 & 2.6 & 8.9 \\
\hline Hippocampus & 4.5 & 3.1 & 6.9 & 5.1 & 2.0 & 9.2 & 5.2 & 3.1 & 9.8 \\
\hline Insular cortex & 4.0 & 3.2 & 4.9 & 4.1 & 2.9 & 5.3 & 4.6 & 2.2 & 8.5 \\
\hline Lateral temporal cortex & 4.3 & 3.1 & 5.6 & 3.9 & 2.9 & 5.0 & 5.1 & 2.7 & 9.4 \\
\hline Midbrain & 6.4 & 3.0 & 14.0 & 6.6 & 2.5 & 13.0 & 5.5 & 2.9 & 11.7 \\
\hline Occipital cortex & 3.8 & 3.0 & 4.6 & 3.4 & 2.5 & 4.5 & 4.4 & 2.5 & 7.0 \\
\hline Orbitofrontal cortex & 5.4 & 3.2 & 12.2 & 4.0 & 2.8 & 5.3 & 5.1 & 2.8 & 9.1 \\
\hline Parietal cortex & 4.0 & 3.2 & 5.2 & 3.7 & 2.9 & 4.5 & 4.7 & 2.6 & 7.7 \\
\hline PCC & 4.3 & 2.5 & 6.3 & 4.4 & 2.4 & 8.0 & 5.4 & 2.7 & 8.4 \\
\hline Pons & 4.5 & 3.4 & 6.0 & 4.4 & 2.4 & 8.0 & 6.0 & 3.9 & 11.7 \\
\hline
\end{tabular}

There was no significant difference of the $\mathrm{BP}_{\mathrm{ND}}$ values in any region among the three groups.

parenchymal binding between healthy volunteers and MS patients. However, contrast-enhancing lesions did show a significantly higher $\left[{ }^{11} \mathrm{C}\right] \mathrm{PBR} 28$ binding compared to contralateral NAWM [3].

Although our study focused on relapsing-remitting MS only and specifically aimed at Gd-enhancing lesions, using $\left[{ }^{18}\right.$ F]FEDAA1106 as a new TSPO ligand, we were not able to reproduce these earlier results. This might be due to the specific features of $\left[{ }^{18} \mathrm{~F}\right]$ FEDAA1106, which we will discuss in the following in further detail.

The time-activity curves of $\left[{ }^{18} \mathrm{~F}\right]$ FEDAA1106 showed slower kinetics in the white matter than in the gray

Table 2 Regional VT values among MS patients and healthy controls

\begin{tabular}{|c|c|c|c|c|c|c|c|c|c|}
\hline \multirow[t]{2}{*}{ Region } & \multicolumn{3}{|c|}{ Six MS naive } & \multicolumn{3}{|c|}{ Three MS treatment $(+)$} & \multicolumn{3}{|c|}{ Five HC } \\
\hline & Mean & Min & Max & Mean & Min & Max & Mean & Min & Max \\
\hline Whole gray matter & 14.0 & 11.8 & 17.2 & 10.1 & 7.8 & 13.8 & 14.0 & 7.2 & 17.8 \\
\hline ACC & 14.8 & 11.5 & 19.2 & 9.7 & 7.3 & 14.4 & 13.8 & 5.9 & 19.4 \\
\hline Caudate & 12.8 & 10.5 & 16.2 & 10.2 & 8.0 & 14.1 & 13.5 & 7.5 & 17.3 \\
\hline Putamen & 14.7 & 12.0 & 18.6 & 9.4 & 7.8 & 12.0 & 13.5 & 8.1 & 16.9 \\
\hline Thalamus & 15.3 & 13.2 & 20.6 & 13.3 & 9.5 & 20.3 & 15.9 & 6.4 & 19.3 \\
\hline Cerebellum & 14.9 & 12.6 & 17.6 & 10.5 & 8.4 & 14.3 & 14.1 & 7.4 & 18.6 \\
\hline Frontal cortex & 14.9 & 12.9 & 17.2 & 10.7 & 8.1 & 14.6 & 14.7 & 7.3 & 19.1 \\
\hline Hippocampus & 12.8 & 10.1 & 14.5 & 12.1 & 7.3 & 21.1 & 11.5 & 6.2 & 14.0 \\
\hline Insular cortex & 14.1 & 12.3 & 19.0 & 10.7 & 8.3 & 14.2 & 13.9 & 7.2 & 19.8 \\
\hline Lateral temporal cortex & 14.2 & 11.8 & 17.6 & 9.8 & 8.1 & 13.0 & 14.1 & 7.4 & 17.8 \\
\hline Midbrain & 14.4 & 9.7 & 22.4 & 11.0 & 7.3 & 18.0 & 10.9 & 6.6 & 13.8 \\
\hline Occipital cortex & 14.6 & 11.9 & 18.6 & 10.1 & 7.4 & 13.1 & 14.5 & 8.0 & 18.8 \\
\hline Orbitofrontal cortex & 19.4 & 12.0 & 44.5 & 10.8 & 8.3 & 14.5 & 14.7 & 7.8 & 20.2 \\
\hline Parietal cortex & 14.4 & 12.4 & 18.2 & 9.8 & 7.4 & 13.3 & 14.1 & 7.2 & 18.5 \\
\hline PCC & 16.2 & 12.7 & 25.2 & 11.9 & 8.0 & 19.6 & 15.8 & 8.4 & 23.2 \\
\hline Pons & 13.7 & 11.3 & 17.7 & 18.0 & 7.9 & 38.0 & 12.9 & 10.2 & 15.6 \\
\hline
\end{tabular}

There was no significant difference of the VT values in any region among the three groups. 
Table 3 Number of MS lesions and sizes of the 5 largest MS lesions in each subject

\begin{tabular}{|c|c|c|c|c|c|c|c|c|}
\hline \multirow[t]{2}{*}{ Subject } & \multicolumn{2}{|c|}{ Number of MS lesions } & \multirow[t]{2}{*}{$\mathrm{Gd}(+)$} & \multicolumn{5}{|c|}{ Sizes of five largest MS plaques $\left(\mathrm{cm}^{3}\right)$} \\
\hline & Total number & T2 and/or FLAIR high & & MSL1 & MSL2 & MSL3 & MSL4 & MSL5 \\
\hline A & 14 & 13 & 2 & 0.3 & 0.2 & 0.1 & $0.1^{a}$ & 0.1 \\
\hline B & 20 & 18 & 6 & 6.2 & 4.3 & 2.9 & 1.6 & 0.7 \\
\hline C & 42 & 42 & 4 & $1.3^{\mathrm{a}}$ & 1.2 & 1.1 & 1.0 & 0.8 \\
\hline D & 25 & 25 & 3 & 0.8 & 0.6 & 0.6 & 0.6 & 0.5 \\
\hline $\mathrm{E}$ & 31 & 31 & 20 & 0.6 & 0.6 & 0.4 & 0.4 & $0.2^{a}$ \\
\hline$F$ & 29 & 29 & 3 & 15 & 4.0 & 1.7 & 1.6 & 1.5 \\
\hline G & 10 & 10 & 5 & 10 & 1.8 & $0.2^{\mathrm{a}}$ & 0.1 & 0.1 \\
\hline $\mathrm{H}$ & 30 & 30 & 3 & 0.7 & 0.4 & 0.4 & $0.3^{\mathrm{a}}$ & 0.2 \\
\hline I & 10 & 10 & 2 & $0.7^{\mathrm{a}}$ & 0.3 & 0.2 & 0.1 & 0.1 \\
\hline
\end{tabular}

${ }^{\mathrm{a}} \mathrm{Gd}$-enhanced MS lesions. Other values were MS lesions which showed T2 and/or FLAIR high intensity but not Gd-enhanced MS lesions. As some MS lesions show both Gd-enhanced and T2 and/or FLAIR high intensity, the total number of MS lesions is not the sum of T2 and/or FLAIR high-intensity lesions and Gd-enhanced lesions.

matter, and radioactivity increased during the PET scan time (up to $150 \mathrm{~min}$ ) in some subjects (data not shown). Due to this, the 2TC model did not converge well. Therefore, white matter might not be an appropriate region for data evaluation using a $2 \mathrm{TC}$ model with $\left[{ }^{18} \mathrm{~F}\right]$ FEDAA1106.

Another reason possibly obscuring a potential difference of TSPO binding between patients with MS and healthy controls is the 'non-binder' issue for TSPO imaging. 'Non-binders' have been reported for $\left[{ }^{11} \mathrm{C}\right]$ PBR28 in one out of ten subjects [12]. They showed only very low binding to TSPO. It is reported that there are three different affinity states (high, mixed, and low) for TSPO binding, and it is only recently discovered that genetic polymorphism underlies the binder - non-binder difference [13]. The importance of evaluation of TSPO polymorphisms has been emphasized recently [14-16]. The phenomenon is considered to be common for the newer TSPO radioligands with $\left[{ }^{11} \mathrm{C}\right] \mathrm{PK} 11195$ probably being the only exception. Although the existence of different binding states has not been reported for $\left[{ }^{18} \mathrm{~F}\right]$
FEDAA1106 yet, it has been reported for $\left[{ }^{11} \mathrm{C}\right] \mathrm{DAA} 1106$ [17]. As FEDAA1106 has a similar chemical structure to that of DAA1106, FEDAA1106 is likely to show similar properties and probably will exhibit different binding states as like all newer TSPO ligands including PBR28. There is approximately a 50-fold difference between high and low affinity binders for PBR28 causing the phenomenon of non-binders. For DAA1106, DPA713, and PBR111, the difference between high- and low-affinity binders is about fivefold. The extent of differences between high- and low-affinity binders for FEDAA1106, and its relative impact awaits further study. This information was not available at the time this study was conducted. In future studies, checking the binding state will allow subjects to be stratified into different binding status groups, which might help detect the group differences between patients and healthy controls.

\section{Feasibility of estimation of $B P_{N D}$ and VT for MS lesions}

$\mathrm{BP}_{\mathrm{ND}}$ and VT calculated by a 2TC model were not able to quantitatively characterize MS lesions. Previous studies

Table $4 \mathrm{BP}_{\mathrm{ND}}$ and VT values for the five largest MS lesions in 9 MS patients

\begin{tabular}{|c|c|c|c|c|c|c|c|c|c|c|}
\hline \multirow[t]{2}{*}{ Subject } & \multicolumn{5}{|c|}{$\mathrm{BP}_{\mathrm{ND}}$} & \multicolumn{5}{|c|}{ VT } \\
\hline & MSL1 & MSL2 & MSL3 & MSL4 & MSL5 & MSL1 & MSL2 & MSL3 & MSL4 & MSL5 \\
\hline A & - & 1.0 & - & $5.0^{\mathrm{a}}$ & 4.2 & - & 1.6 & - & $17.1^{\mathrm{a}}$ & 4.4 \\
\hline B & 8.2 & 3.9 & 5.5 & 15.7 & 6.4 & 15.1 & 10.6 & 11.8 & 13.7 & 11.1 \\
\hline C & $2.4^{\mathrm{a}}$ & 14.1 & 5.7 & 4.2 & 9.0 & $12.6^{\mathrm{a}}$ & 9.4 & 10.2 & 15.9 & 4.8 \\
\hline D & 4.3 & - & 9.3 & - & 3.3 & 7.1 & - & 5.5 & - & 6.8 \\
\hline$E$ & 24.5 & - & 12.8 & 9.7 & $7.9^{\mathrm{a}}$ & 7.2 & - & 19.7 & 11.9 & $10.2^{a}$ \\
\hline$F$ & 26.9 & 17.2 & 3.4 & 19.4 & - & 22.9 & 15.1 & 8.8 & 16.5 & - \\
\hline G & 4.7 & 7.7 & $15.4^{\mathrm{a}}$ & 0.3 & - & 11.3 & 11.6 & $32.4^{\mathrm{a}}$ & 8.6 & - \\
\hline $\mathrm{H}$ & 5.0 & - & 15.9 & $26.3^{\mathrm{a}}$ & 5.4 & 7.0 & 6.6 & 37.5 & $12.0^{\mathrm{a}}$ & 5.5 \\
\hline I & $12.0^{\mathrm{a}}$ & 4.0 & 27.3 & 16.8 & 4.0 & $35.6^{\mathrm{a}}$ & 30.8 & 4.6 & 21.6 & 6.6 \\
\hline
\end{tabular}

${ }^{\mathrm{a}} \mathrm{Gd}$-enhanced MS lesions. Other values were MS lesions which showed T2 and/or FLAIR high intensity but not Gd-enhanced MS lesions. 
Table $5 \mathrm{BP}_{\mathrm{ND}}$ and VT values of the combined regions in 9 MS patients

\begin{tabular}{lccccc}
\hline Subject & \multicolumn{2}{c}{ BP $_{\text {ND }}$} & & \multicolumn{2}{c}{ VT } \\
\cline { 2 - 3 } & Gd (+) & $\begin{array}{r}\text { T2 and/or } \\
\text { FLAIR high }\end{array}$ & Gd (+) & $\begin{array}{r}\text { T2 and/or } \\
\text { FLAIR high }\end{array}$ \\
\hline A & 12.7 & 2.6 & & 34.4 & 4.9 \\
B & 26.6 & 5.7 & & 28.7 & 11.1 \\
C & 5.8 & 4.5 & & 21.0 & 9.1 \\
D & 3.9 & 5.9 & & 4.8 & 7.6 \\
E & 5.9 & 6.3 & & 9.8 & 13.4 \\
F & 12.5 & 13.3 & & 13.5 & 13.8 \\
G & 3.4 & 5.0 & & 10.3 & 11.6 \\
H & 60.1 & 4.6 & 9.0 & 9.3 \\
I & 11.3 & 4.0 & 35.5 & 12.8 \\
\hline
\end{tabular}

using noise simulation of $\left[{ }^{18}\right.$ F]FEDAA1106 PET data reported that $10 \%$ noise-added data generated more than $25 \%$ of coefficient of variance in the dorsolateral prefrontal cortex [9]. Considering the small size of the MS lesions, the actual time-activity curves could be much noisier than the aforementioned simulated $10 \%$ noise-added data. The unstable estimation of the above outcome measures for MS lesions might be in line with the results from the simulation analysis.

\section{Visual inspection of PET images}

A previous PET TSPO study using $\left[{ }^{11} \mathrm{C}\right]$ PBR28 showed high uptake in the white matter outside of the MRIdefined MS lesions [3]. Some of the $\left[{ }^{11} \mathrm{C}\right]$ PBR28 highuptake areas developed to a new Gd-enhanced lesion detected in the 1-month follow-up study. To detect such a change, parametric images could be helpful. Although an approach to de-noise the data in order to improve the parametric images has been reported for $\left[{ }^{18} \mathrm{~F}\right]$ FEDAA1106 [18], the $\mathrm{BP}_{\mathrm{ND}}$ images were not of sufficient quality for visual inspection (i.e., diagnostic practice) due to the low signal-to-noise ratio of $\left[{ }^{18} \mathrm{~F}\right] \mathrm{FEDAA} 1106$ $\mathrm{BP}_{\mathrm{ND}}$ PET images.

Although SUV and VT images calculated by the Logan plot were generated in this study, both SUV and VT have some drawbacks for $\left[{ }^{18}\right.$ F]FEDAA1106. SUV values did not always correspond to $\mathrm{BP}_{\mathrm{ND}}$ or VT values. VT by the Logan plot was reported to be underestimated compared with VT by the 2TC model [9]. In both sets of

\section{A) $\mathrm{Gd}(+)$, T2/Flair (+) , PET(+)}

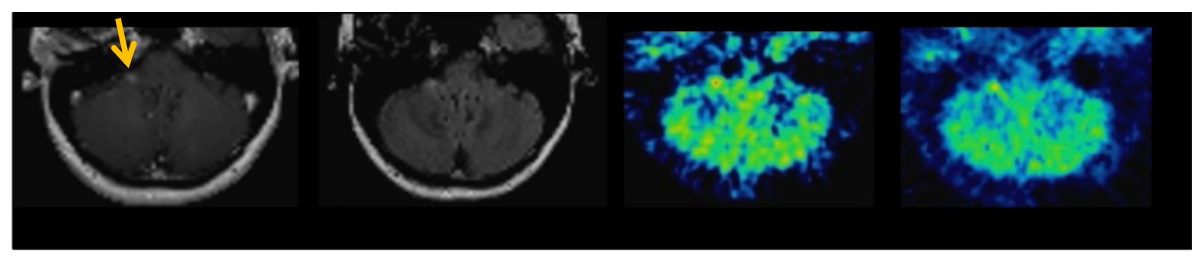

B) $\mathrm{Gd}(+)$, T2/Flair (+) , PET(-)

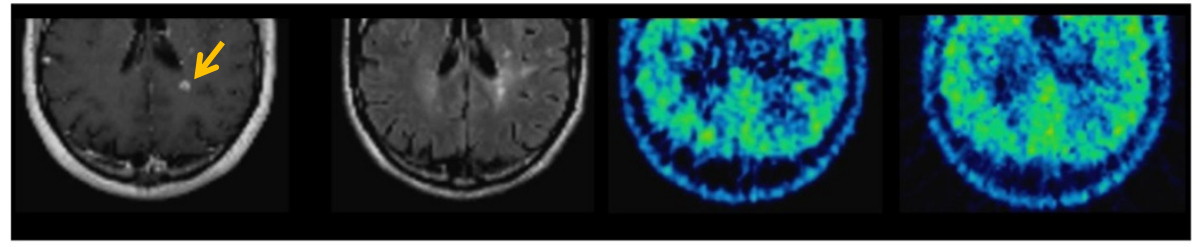

C) Gd(-), T2/Flair (+) , PET(-)

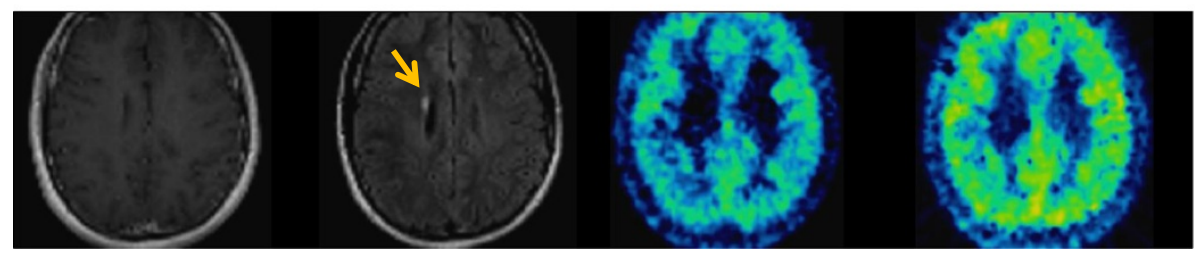

T1Gd

FLAIR

SUV

Logan VT

Figure 2 Typical MRI images and corresponding PET images for MRI-defined MS lesions. There were three patterns as follows: (A) Gdenhanced and high intensity in T2/FLAIR images and high uptake in PET images. The images are from subject A. The arrow indicates the MS lesion. (B) Gd-enhanced and high intensity in T2/FLAIR but not high uptake in PET images. The images are from subject D. (C) Not Gd-enhanced but high intensity in T2/FLAIR and not high uptake in PET images. 
images, there was no detectable high uptake in the MRIdefined MS lesions, with the exception of one MS lesion (Figure 2). In SUV and VT images, high nonspecific uptake in the surrounding gray and white matter might obscure the changes in the MS lesions and potential changes outside of MS lesions.

The reason why one MS lesion showed high uptake, while other MS lesions did not, could not be fully explained. Although MS lesions might have different features depending on their duration, the time span between the MRI screening and the PET scan of the patient with only MS lesion that showed high uptake was 4 days, and this time span was not different from the average 3.6-day-long time span of all the nine subjects. The MS lesion was located in the right middle cerebellar peduncle close to the brain surface facing the cistern magna. This location could result in less signal spillover and thereby higher contrast to the surrounding tissues. Additionally, lesions, even though they are Gdenhancing, might still differ with respect to the histological characteristics as well as the respective content and activation of microglia reflected by different amounts of TSPO binding, but this could not be further evaluated in our study.

The PET machine used in this study had a limited spatial resolution, causing most of the MS lesions, which are small, to be affected by a partial volume effect. Higher-resolution PET machines might be an advantage in investigating MS lesions in the future.

\section{Conclusions}

In conclusion, the present study does not endorse the usefulness of $\left[{ }^{18} \mathrm{~F}\right]$ FEDAA1106 as a PET radioligand for the differentiation of patients with MS from healthy controls or for the detection of active MS lesions in patients. Even though information on the binding status had been available, the radioligand still showed some unfavorable kinetic characteristics, which would likely hinder the further usage of it in a broader clinical context. ${ }^{18} \mathrm{~F}$ radioligands with faster kinetics and lower nonspecific binding than $\left[{ }^{18} \mathrm{~F}\right]$ FEDAA1106 would have greater potential for the evaluation of patients with MS. Genetic information about TSPO binding must be taken into account in future studies to allow patient stratification.

\section{Competing interests}

TZ, MSM, AT, and AH are employees of Bayer Health Care. VC and CCR are consultants for Bayer Healthcare. The other co-authors have no competing interests.

\section{Authors' contributions}

$\mathrm{AH}$ and $\mathrm{CH}$ led the study in total. All authors participated in the development of the study design. FP, JH, and NAT recruited subjects. SN produced the PET radioligand. BG, PS, and AV performed PET measurements. AT (Takano) and AV analyzed the PET image data. TK analyzed the MRI data. All authors contributed to the interpretation of the study results. AT (Takano) drafted the manuscript. All authors critically reviewed the manuscript and approved the final manuscript.

\section{Acknowledgments}

The authors thank all the members of the PET group at the Karolinska Institutet PET Center for their assistance in the PET study. The study was sponsored by Bayer HealthCare.

\section{Author details}

'Center for Psychiatric Research, Department of Clinical Neuroscience, Karolinska Institutet, Stockholm SE-171 77, Sweden. ${ }^{2}$ Department of Clinical Neuroscience, Karolinska Institutet, Stockholm SE-171 77, Sweden.

${ }^{3}$ Department of Nuclear Medicine and Centre for PET, Austin Health, Heidelberg 3084, Australia. ${ }^{4}$ Department of Neurology, Austin Health, Heidelberg 3084, Australia. ${ }^{5}$ Karolinska Trial Alliance, Karolinska University Hospital, Stockholm SE-141 86, Sweden. ${ }^{6}$ Bayer Health Care AG, Berlin, Germany,

Received: 30 January 2013 Accepted: 3 April 2013 Published: 24 April 2013

\section{References}

1. Cosenza-Nashat M, Zhao ML, Suh HS, Morgan J, Natividad R, Morgello S, Lee SC: Expression of the translocator protein of $18 \mathrm{kDa}$ by microglia, macrophages and astrocytes based on immunohistochemical localization in abnormal human brain. Neuropathol Appl Neurobiol 2009, 35:306-328.

2. Banati RB, Newcombe J, Gunn RN, Cagnin A, Turkheimer F, Heppner F, Price G, Wegner F, Giovannoni G, Miller DH, Perkin GD, Smith T, Hewson AK, Bydder G, Kreutzberg GW, Jones T, Cuzner ML, Myers R: The peripheral benzodiazepine binding site in the brain in multiple sclerosis: quantitative in vivo imaging of microglia as a measure of disease activity. Brain 2000, 123(Pt 11):2321-2337.

3. Oh U, Fujita M, Ikonomidou VN, Evangelou IE, Matsuura E, Harberts E, Fujimura Y, Richert ND, Ohayon J, Pike WW, Zhang Y, Zoghbi SS, Innis RB, Jacobson S: Translocator protein PET imaging for glial activation in multiple sclerosis. J Neuroimmune Pharmacol 2011, 6:354-61.

4. Vas A, Shchukin Y, Karrenbauer VD, Cselenyi Z, Kostulas K, Hillert J, Savic I, Takano A, Halldin C, Gulyas B: Functional neuroimaging in multiple sclerosis with radiolabelled glia markers: preliminary comparative PET studies with $\left[{ }^{11} \mathrm{C}\right]$ vinpocetine and $\left[{ }^{11} \mathrm{C}\right] \mathrm{PK} 11195$ in patients. J Neurol SCi 2008, 264:9-17.

5. Zhang MR, Maeda J, Ogawa M, Noguchi J, Ito T, Yoshida Y, Okauchi T, Obayashi S, Suhara T, Suzuki K: Development of a new radioligand, $\mathrm{N}$-(5-fluoro-2-phenoxyphenyl)-N-(2-[18F]fluoroethyl-5-methoxybenzyl) acetamide, for pet imaging of peripheral benzodiazepine receptor in primate brain. J Med Chem 2004, 47:2228-2235.

6. Takano A, Gulyas B, Varrone A, Karlsson P, Sjoholm N, Larsson S, Jonsson C, Odh R, Sparks R, Al Tawil N, Hoffmann A, Zimmermann T, Thiele A, Halldin C: Biodistribution and radiation dosimetry of the $18 \mathrm{kDa}$ translocator protein (TSPO) radioligand $\left[{ }^{18} \mathrm{~F}\right] \mathrm{FEDAA} 1106$ : a human whole-body PET study. Eur J Nucl Med Mol Imaging 2011, 38:2058-2065.

7. Wienhard K, Dahlbom M, Eriksson L, Michel C, Bruckbauer T, Pietrzyk U, Heiss WD: The ECAT EXACT HR: performance of a new high resolution positron scanner. J Comput Assist Tomogr 1994, 18:110-118.

8. Debruyne JC, Versijpt J, Van Laere KJ, De Vos F, Keppens J Strijckmans K, Achten E, Slegers G, Dierckx RA, Korf J, De Reuck JL: PET visualization of microglia in multiple sclerosis patients using $\left[{ }^{11} \mathrm{C}\right] \mathrm{PK} 11195$. Eur J Neurol 2003, 10:257-264

9. Fujimura $Y$, Ikoma $Y$, Yasuno F, Suhara T, Ota M, Matsumoto R, Nozaki S, Takano A, Kosaka J, Zhang MR, Nakao R, Suzuki K, Kato N, Ito H: Quantitative analyses of 18F-FEDAA1106 binding to peripheral benzodiazepine receptors in living human brain. J Nucl Med 2006, 47:43-50.

10. Logan J, Fowler JS, Volkow ND, Wolf AP, Dewey SL, Schlyer DJ, MacGregor RR, Hitzemann R, Bendriem B, Gatley SJ, Christman DR: Graphical analysis of reversible radioligand binding from time-activity measurements applied to [N-11C-methyl]-(-)-cocaine PET studies in human subjects. J Cereb Blood Flow Metab 1990, 10:740-747.

11. Vowinckel E, Reutens D, Becher B, Verge G, Evans A, Owens T, Antel JP. PK11195 binding to the peripheral benzodiazepine receptor as a marker 
of microglia activation in multiple sclerosis and experimental autoimmune encephalomyelitis. J Neurosci Res 1997, 50:345-353.

12. Brown AK, Fujita M, Fujimura Y, Liow JS, Stabin M, Ryu YH, Imaizumi M, Hong J, Pike WW, Innis RB: Radiation dosimetry and biodistribution in monkey and man of ${ }^{11} \mathrm{C}$-PBR28: a PET radioligand to image inflammation. J Nucl Med 2007, 48:2072-2079.

13. Owen DR, Yeo AJ, Gunn RN, Song K, Wadsworth G, Lewis A, Rhodes C, Pulford DJ, Bennacef I, Parker CA, Stjean PL, Cardon LR, Mooser VE, Matthews PM, Rabiner EA, Rubio JP: An 18-kDa translocator protein (TSPO) polymorphism explains differences in binding affinity of the PET radioligand PBR28. J Cereb Blood Flow Metab 2012, 32:1-5

14. Guo Q, Owen DR, Rabiner EA, Turkheimer FE, Gunn RN: Identifying improved TSPO PET imaging probes through biomathematics: the impact of multiple TSPO binding sites in vivo. Neuroimage 2012, 60:902-910.

15. Mizrahi R, Rusjan PM, Kennedy J, Pollock B, Mulsant B, Suridjan I, De Luca V, Wilson AA, Houle S: Translocator protein (18 kDa) polymorphism (rs6971) explains in-vivo brain binding affinity of the PET radioligand $\left[{ }^{18} \mathrm{~F}\right]$-FEPPA. J Cereb Blood Flow Metab 2012, 32:968-972.

16. Kreisl WC, Jenko KJ, Hines CS, Hyoung Lyoo C, Corona W, Morse CL, Zoghbi SS, Hyde T, Kleinman JE, Pike WW, McMahon FJ, Innis RB: A genetic polymorphism for translocator protein $18 \mathrm{kDa}$ affects both in vitro and in vivo radioligand binding in human brain to this putative biomarker of neuroinflammation. J Cereb Blood Flow Metab 2013, 33:53-58.

17. Owen DR, Gunn RN, Rabiner EA, Bennacef I, Fujita M, Kreis I WC, Innis RB, Pike WW, Reynolds R, Matthews PM, Parker CA: Mixed-affinity binding in humans with 18-kDa translocator protein ligands. J Nucl Med 2011, 52:24-32.

18. Shidahara M, Ikoma Y, Seki C, Fujimura Y, Naganawa M, Ito H, Suhara T, Kanno I, Kimura Y: Wavelet denoising for voxel-based compartmental analysis of peripheral benzodiazepine receptors with [18]F-FEDAA1106. Eur J Nucl Med Mol Imaging 2008, 35:416-423.

doi:10.1186/2191-219X-3-30

Cite this article as: Takano et al: In vivo TSPO imaging in patients with multiple sclerosis: a brain PET study with $\left[{ }^{18} \mathrm{~F}\right] \mathrm{FEDAA} 1106$. EJNMMI

Research 2013 3:30.

\section{Submit your manuscript to a SpringerOpen ${ }^{\circ}$ journal and benefit from:}

- Convenient online submission

- Rigorous peer review

- Immediate publication on acceptance

- Open access: articles freely available online

- High visibility within the field

- Retaining the copyright to your article 